\title{
BELBIC Tuned PI Controller Based Chopper Driven PMDC Motor
}

\author{
Muthukrishnan Subramaniam1, Murugananth Gopalraj2 ${ }^{*}$, Saravana Sundaram Sakthivelu³, \\ Samidurai Kandasamy ${ }^{4}$ \\ ${ }^{1}$ Sri Eshwar College of Engineering, Coimbatore, India \\ ${ }^{2}$ Ahalia School of Engineering and Technology, Palakkad, India \\ ${ }^{3}$ Hindusthan College of Engineering and Technology, Coimbatore, India \\ ${ }^{4}$ Vidya Vikas College of Engineering and Technology, Tiruchengode, India \\ Email: *gmurugananth@gmail.com \\ Received $* * * * 2016$ \\ Copyright (C) 2016 by authors and Scientific Research Publishing Inc. \\ This work is licensed under the Creative Commons Attribution International License (CC BY). \\ http://creativecommons.org/licenses/by/4.0/

cC) (i) Open Access

\begin{abstract}
In orthopaedic surgeries, permanent magnet DC motors are used to drill the bone and fix the screws. The Motor drive employs an inner current and outer speed control loop with a conventional or modern controller. To enhance the performance of the drive, this paper proposes a Brain Emotional Logic Based Intelligent Controller based chopper drive. The proposed drive scheme has been simulated using Matlab/Simulink and physically realized for validation. A comparative analysis has been made between the conventional PI controller based drive and the proposed system in order to prove that the proposed scheme has an edge over the traditional PI controller scheme counterpart.
\end{abstract}

\section{Keywords}

BELBIC, Chopper Drive, PMDC Motor, Orthopedic Surgeries, Osteosynthesis, PI Controller, Steady State and Transient State Responses

\section{Introduction}

Osteosynthesis is the surgical practice of reducing and stabilizing fractured bones using mechanical connectors such as metal plates, wires or screws. It is done in three phases namely screw insertion, tightening and stripping. In Osteosynthesis low power electric motors such as permanent magnet DC (PMDC) motors are used to make joints in the fractured bones. Depending on the nature of fracture, a metal plate or screws will be attached with

${ }^{*}$ Corresponding author. 
the fractured bone. Generally novice surgeons used to practice Osteosynthesis phenomenon in synthetic bones rather than live patients. This is because if carried out in live patients, the over tightening of screws may result in additional bone fracture [1] [2].

During 1990s research works were carried out on the drilling tools used in orthopaedic surgeries with a focus on their mechanical parameters. The main focus of the researchers [3] [4] pointed on the mechanical parameters viz., size of drill bit, depth of penetration, temperature rise etc., It is known that mechanical energy is converted into thermal energy during drilling. The heat generated in the drill bit is proportional to the drill speed and feed rate as discussed elsewhere by [5]-[8]. A high drilling speed has been suggested as it reduces the drilling time and also temperature rise in bones. The amount of temperature rise depends on drill geometry, diameter, rotational speed, feed rate, axial thrust force and initial drill bit temperature [9]-[12]. A drill speed of range from 300 rpm to 2000 rpm has been suggested [13] [14] to keep the temperature rise within acceptable limits. At the outset, it is the speed and the duration of drill decides the temperature rise in bones during the course of drilling.

In the beginning of this century, robot-assisted surgeries came into existence. A haptic simulator which computes the drilling forces and torques based on reliable metal removing theorem has been proposed [15]-[17]. Based on this theorem, a robotized drilling module has been developed [16]. A mechatronic screw driver devised [17] controls the tapping depth and prevents over tightening of screws. Conventional PI or fuzzy logic controllers have been proposed for the speed control of PMDC motor in mechatronic drilling systems [18]-[20]. A Fuzzy logic based DC motor drive [18] has been suggested for accurate drilling which uses current control method. A closed loop chopper controlled drive with a traditional PI and PID controller has been proposed for the drilling process in orthopaedic surgeries [19]. The performance of the PI controller has been improved using various anti-windup techniques [20].

The current trend in design of control algorithms is to use the biologically inspired methods such as neural networks and other evolutionary algorithms, in order to solve and analyse complex computational problems. Recently, a new type of intellectual technique based on emotion processing mechanism of the brain was introduced in early 2000's [21]. The controller designed using this technique is termed as Brain Emotional Learning Based Intelligent Controller (BELBIC). This controller is used for control and decision making processes, which is inspired by the limbic system of mammalian brain. The control action of BELBIC controller is based on the sensory inputs and the emotional cues. It is a dual feedback system which consumes less processing time. Several attempts have been made [22]-[24] to model the emotional behavior of human brain. The computational models with Amygdala and Context processing was introduced and subsequently named the model as Brain Emotional Learning (BEL) model. In the past decade of years, the BELBIC controller has been used with minimal modifications, in control devices for industrial applications [25]. The Matlab/Simulink model of the controller was proposed [26] and the system was simulated as an emotional intelligent controller for interline power flow controller. The intelligent controller designed by them improved the transient stability of the power systems.

This paper deals with the performance study of proposed Brain Emotional Logic Based Intelligent Controller (BELBIC) based chopper for the speed control of PMDC motor used in bone drilling and screwing applications. The feed rate of bone drilling is maintained constant and the drive is tested for various speed-torque conditions. The bone density which offers resistive force while drilling acts as a load to the motor. The simulation and experimental results are presented to validate the proposed scheme. These results are in close agreement with each other. The performance study reveals that the use of the proposed BELBIC based chopper controlled drive results in improved steady state and transient state responses in terms of maximum overshoot, steady state error and motor deceleration time when compared to its traditional counterpart.

\section{PMDC Based Chopper Drive}

\subsection{PMDC Motor}

PMDC Motors possess linear speed torque characteristics and have high stalling torque and reduced power loss. They are compact in size and have wide operating speed range. Owing to these virtues, these motors are being used in orthopedic surgeries. The block diagram representing closed loop model of PMDC motor depicted in Figure 1 has been developed from its equivalent circuit shown in Figure 2 and its corresponding equations portrayed from 1 to 6 , where, $V_{a}$-armature supply voltage in $\mathrm{V} ; V_{c}$-induced voltage in $\mathrm{V}$. 


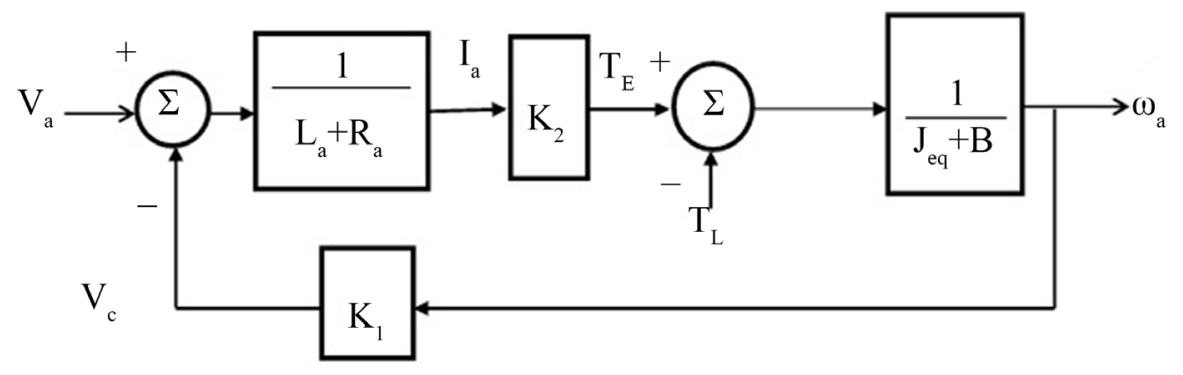

Figure 1. Block Diagram representation of PMDC.

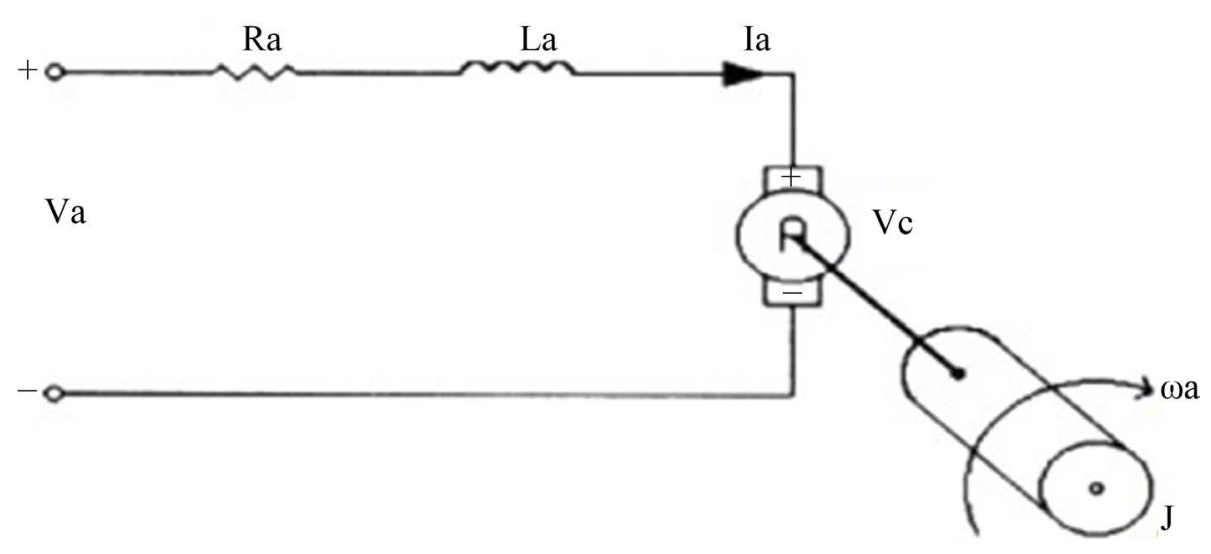

Figure 2. Equivalent circuit model of PMDC motor.

$$
\begin{gathered}
V_{a}=V_{c}+I_{a} R_{a}+L_{a} \frac{d I_{a}}{d t} \\
V_{c}=K_{1} \omega_{a} \\
T_{E}=T_{L}+B \omega_{a}+J_{e q} \frac{d \omega_{a}}{d t} \\
T_{E}=K_{2} I a
\end{gathered}
$$

$R_{a}$-armature resistance in Ohms

$L_{a}$-armature inductance in $\mathrm{H}$

$I_{a}$-armature current in A

$K_{1}$ —voltage constant in volts sec/rads

$\omega_{a}$-angular speed in rads/sec

$T_{E}$-electromagnetic torque developed $\mathrm{Nm}$

$T_{L}$-load torque in $\mathrm{Nm}$

$J_{e q}$ - total Moment of Inertia of motor and load in $\mathrm{kg} \cdot \mathrm{m}^{2} / \mathrm{s}^{2}$

$\mathrm{B}$-damping Coefficient in Nms

$\mathrm{K}_{2}$ - torque constant in $\mathrm{Nm} / \mathrm{A}$

The differential equations governing the motor model have been obtained using the expressions 1 to 4 as follows.

$$
\begin{gathered}
\frac{d I_{a}}{d t}=-\frac{R_{a}}{L_{a}} I_{a}-\frac{K_{1}}{L_{a}} \omega_{a}+\frac{V_{a}}{L_{a}} \\
\frac{d \omega_{a}}{d t}=\frac{K_{2}}{J_{e q}} I_{a}-\frac{B}{J_{e q}} \omega_{a}-\frac{T_{L}}{J_{e q}}
\end{gathered}
$$




\subsection{Chopper Drive}

It is known that as the field flux of the PMDC motor remains constant, only armature voltage control method can be employed to control its speed. To obtain variable speed, armature voltage is varied. The conventional method employs a variable resistance in series with the armature winding to operate the motor at different speeds. However, this method of speed control is inefficient as the series resistance incurs significant amount of energy loss. Closed loop control is also expensive with this method as far as motors of smaller ratings are concerned. To overcome these drawbacks in particular, chopper controlled drives are being used for the speed control of DC motors. In these drives, the duty cycle of the chopper is varied to obtain variable armature voltage and hence the speed of the motor. The block diagram of the proposed chopper drive has been depicted in Figure 3. It consists of a power electronic switch driven by Pulse Width Modulated (PWM) gating signal, which facilitates variable motor speed. For closed loop operation of the drive, the motor current (I) and speed (N) are fed back. During the course of the orthopaedic surgery, outer speed control and inner current control loops of the proposed drive govern drilling and screwing modes of operation respectively.

\subsubsection{Drilling Mode}

In the Osteosynthesis phenomenon, the bone drilling is the preliminary process. The speed and torque required to drill the bone mainly depends on certain parameters viz. bone density and screw geometry. The torque almost remains constant throughout the period of drilling. The motor speed is proportional to the input voltage of the motor. The difference between the set speed $\left(\mathrm{N}_{\text {ref }}\right)$ and the actual speed $(\mathrm{N})$ is calculated and as error input to the controller. This error input is processed by the controller (conventional PI or proposed BELBIC) and generates necessary PWM gating pulses. These pulses control the conduction period of the switch and in turn the input voltage to the motor. The drilling speed varies in line with motor voltage. The drilling operation is carried out by the outer speed control loop of the chopper drive system.

\subsubsection{Screwing Mode}

In Osteosynthesis process, the screwing of bones is accomplished in three phases viz. insertion, tightening and stripping. The speed and torque requirements are set depends on the phase. It may be noted that the speed required for screwing mode is less than that required for drilling. In the case of drilling mode, relatively higher speed and lower torque are required. The torque is set in terms of current. To tighten the screw, certain amount of torque is required. Increase in torque beyond this value indicates that the screw is being over tightened. Motor draws more current to develop excess torque required during over tightening. To prevent the bones and motor from harmful effects caused by over tightening of screw, screwing operation has to be stopped immediately after the screw is firmly fixed. The inner current control loop which governs the screwing operation stops the motor, when the current drawn by the motor (I) exceeds the set current $\left(\mathrm{I}_{\text {ref }}\right)$.

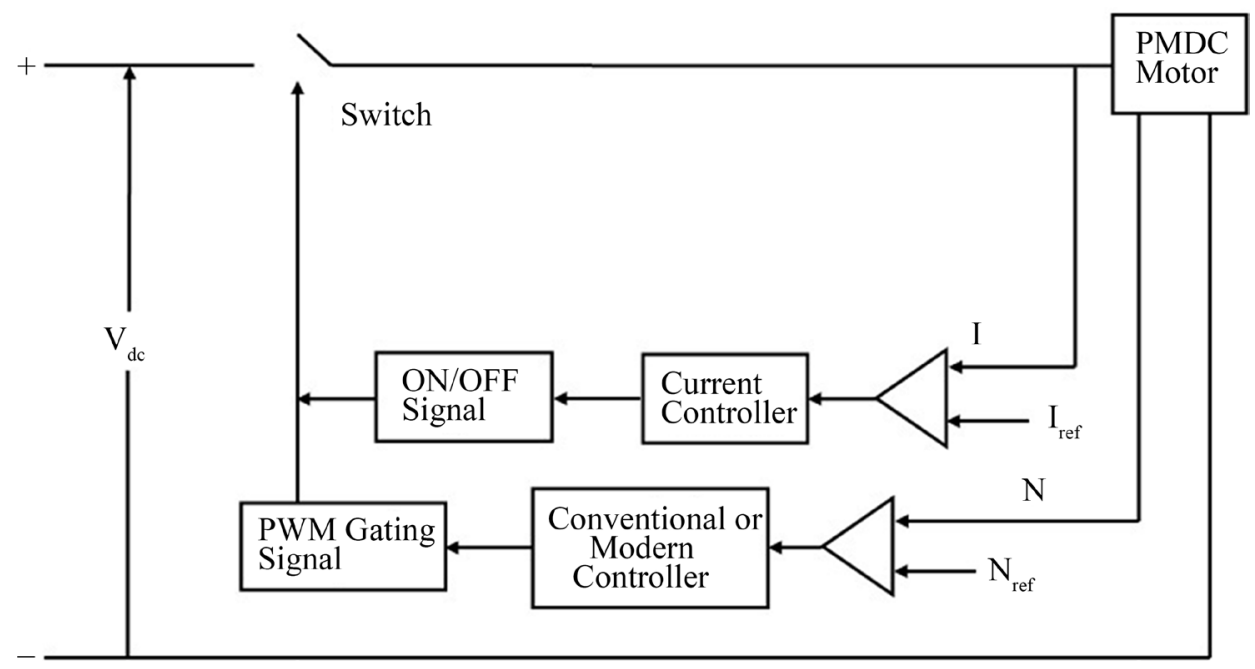

Figure 3. Block diagram of chopper controlled drive for PMDC motor. 


\section{Brain Emotional Learning Based Intelligent Controller}

The structure of the proposed BELBIC algorithm is illustrated in Figure 4. The main parts of the controller which are used in control action are orbitofrontal cortex and amygdala. The sensory input (Si) is given to the thalamus. The amygdala receives the input from thalamus and sensory cortex. The emotional input which is termed as emotional cues is also given to amygdala. The function learning takes place in amygdala. The learning rule of amygdala is given by the Equation (7).

$$
V_{i}=K_{1}\left(E C-A_{i}\right)
$$

where,

$V_{i}$-amygdala gain

$K_{1}$-learning rate in the amygdala

$E C$-emotional cue function

$A_{i}$ - amygdala output

The output of the amygdala $\left(A_{i}\right)$ is governed by the Equation (8).

$$
A_{i}=S_{i} * V_{i}
$$

where, $S_{i}$ is the Sensory input.

The orbitofrontal cortex receives inputs from amygdala, sensor cortex and the emotional cue functions. The learning rule in orbitofrontal cortex is given by the Equation (9).

$$
W_{i}=k_{2}(M O-E C)
$$

where,

$W_{i}$-Orbitofrontal Cortex gain

$k_{2}$-learning rate of orbitofrontal cortex.

$\mathrm{MO}$ - model output.

The output of orbitofrontal cortex $\left(O_{i}\right)$ is given by the Equation (10).

$$
O_{i}=S_{i} * W_{i}
$$

From the output equations of amygdala and orbitofrontal cortex given by Equations 8 and 9, the output function of the model output $(M O)$ can be derived as,

$$
M O=A_{i}-O_{i}
$$

The amygdala does not have the capability to unlearn any emotional response that it ever learned. The function of the orbitofrontal cortex is to response to the any inappropriate response when occurred. The gain functions $k_{1}$ and $k_{2}$ may vary during the control process. In the proposed BELBIC based drive, the error (e) between set speed $\left(N_{\text {ref }}\right)$ and the current speed $(N)$ is utilized as input to the BELBIC controller. The speed error becomes the sensory input. The emotional cue $(E C)$ function is formed with the sensory input and the model

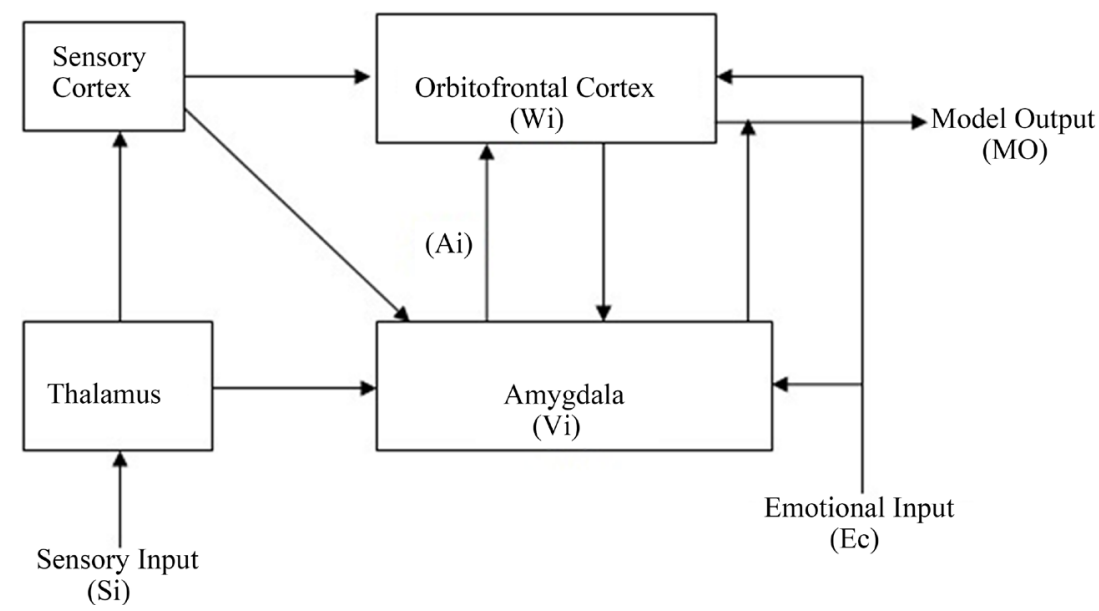

Figure 4. Structure of BELBIC. 
output. It is governed by the Equation (12).

$$
E C=\left[-W_{1} *\left(e * \frac{d}{d t} e\right)+W_{2} * a b s(e)\right] * M O
$$

In Equation (12), $W_{1}$ and $W_{2}$ are the weights assigned for the gain functions. In the proposed BELBIC based chopper drive, the weights are assigned arbitrarily because BELBIC is a learning procedure of trial and error manner as stated by Jamali et al. [24] and Eshan Jafari [26]. As it can be seen there are several tuning parameters for each sensory input. The general algorithm for tuning these parameters is trial and error.

\subsection{Simulation Study of BELBIC Drive}

The proposed BELBIC based chopper drive is simulated using Matlab/Simulink tool. The error between the current speed and set speed is sensed. For performance analysis, both drilling and screwing modes of chopper drive have been simulated. The technical specifications of the PMDC motor used for simulation are given in Table 1. Drilling mode of the drive has been simulated in such a way that the drive runs at set speed on no-load for 3 seconds. The load on the motor has been set after this period. The motor has been made to run with this set value of load for 7 seconds. Dip in speed against the application of load persists only for very few milli-seconds as the controller response is extremely faster. Hence no speed variation found at the end of 3 seconds in Figure 5(a). Running the motor with load for certain duration refers to drilling operation during that period. For screwing mode of operation, the current controller has been made to respond when the current exceeds the set value. Increase in current beyond the set value indicates over tightening of screw. Current is made to exceed at 5.2 seconds to ascertain the response of a current controller. Figure 5(a) \& Figure 5(b) portray the simulation results of the proposed scheme.

\subsection{Experimental Analysis of Proposed Drive Scheme}

The experimental setup has been physically realized based on the setup used for performance evaluation of genetic algorithm based speed control of PMDC motor using a low cost microcontroller [27]. An experimental setup of the proposed drive has been designed and physically realized as portrayed in Figure 6. MOSFET IRF840 is used as switching device for the speed control of PMDC motor. As the MOSFET has the advantages of low on state losses and medium switching frequencies of operation, it is employed in the chopper circuit. The ratings of the motor used for experimental study is given in Table 1.

It may be noted that the ratings of the motor used in simulation and experimental studies are identical. The Peripheral Interface Controller (PIC 16F877A) estimates the actual speed of the motor by obtaining the signals from the reed switch (speed sensor) via its analog to digital converter. The actual speed and reference speed is compared and the PIC controller generates the necessary PWM gating signals to the MOSFET as shown in Figure 7. The generation of PWM signals is governed by the proposed BELBIC algorithms embedded in this PIC controller. The current is measured using the voltage divider network and is compared with reference current. The PIC controller turns off the supply to the motor if the measured current exceeds the reference current. The opto coupler used in the circuit provides isolation between control and power circuit.

Table 1. Specifications of PMDC motor.

\begin{tabular}{cc}
\hline Parameter & Value \\
\hline Output Power $\left(P_{o}\right)$ & $52 \mathrm{~W}$ \\
Input Voltage $\left(V_{a}\right)$ & $9 \mathrm{~V}$ \\
No-Load Speed $\left(N_{o}\right)$ & $4990 \mathrm{rpm}$ \\
Armature Resistance $\left(R_{a}\right)$ & $1 \Omega$ \\
Armature Inductance $\left(L_{a}\right)$ & $0.13 \mathrm{mH}$ \\
Moment of Inertia $(J)$ & $4.8 \mathrm{e}^{-6} \mathrm{~kg}^{-\mathrm{m}^{2}}$ \\
Damping Coefficient $(B)$ & $6.04 \mathrm{e}^{-6} \mathrm{~N}-\mathrm{m} / \mathrm{rads} / \mathrm{sec}$ \\
Voltage Constant $\left(K_{1}\right)$ & $1.7 \mathrm{e}^{-2} \mathrm{volts} / \mathrm{rads} / \mathrm{sec}$ \\
Torque Constant $\left(K_{2}\right)$ & $1.68 \mathrm{e}^{-2} \mathrm{~N}-\mathrm{m} / \mathrm{A}$ \\
\hline
\end{tabular}




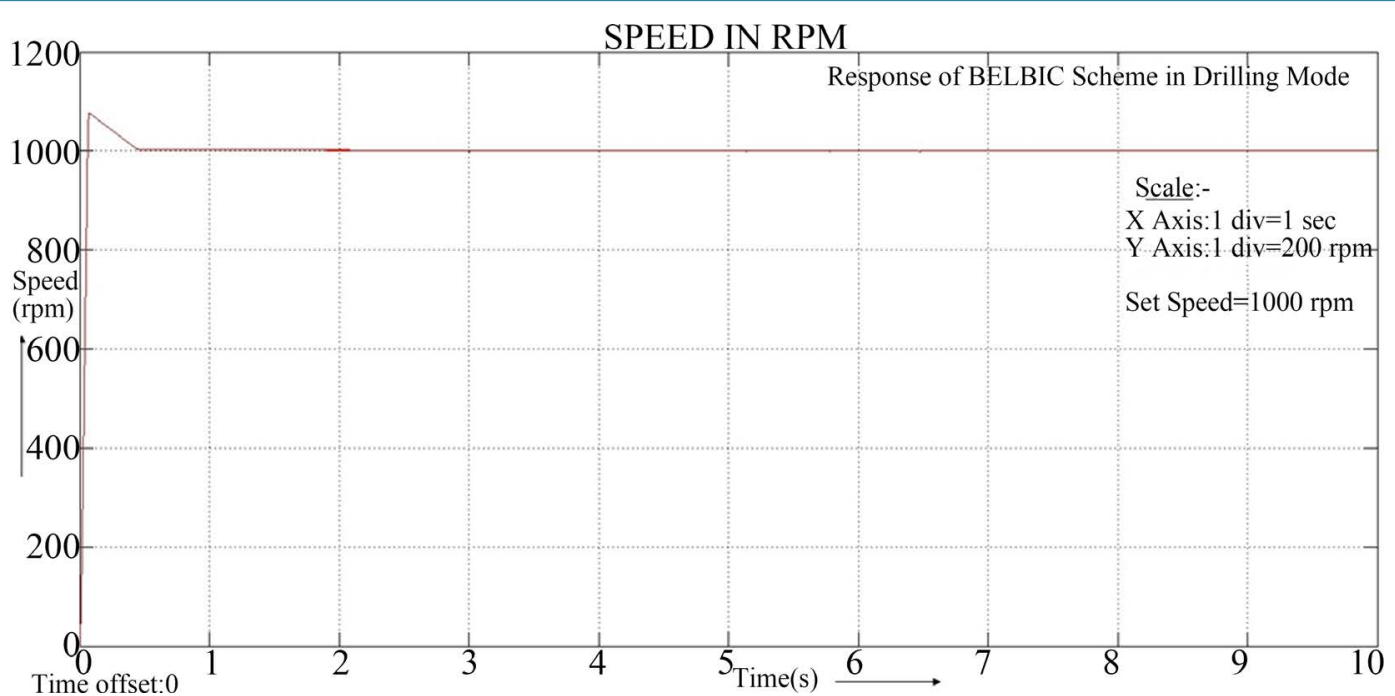

(a)

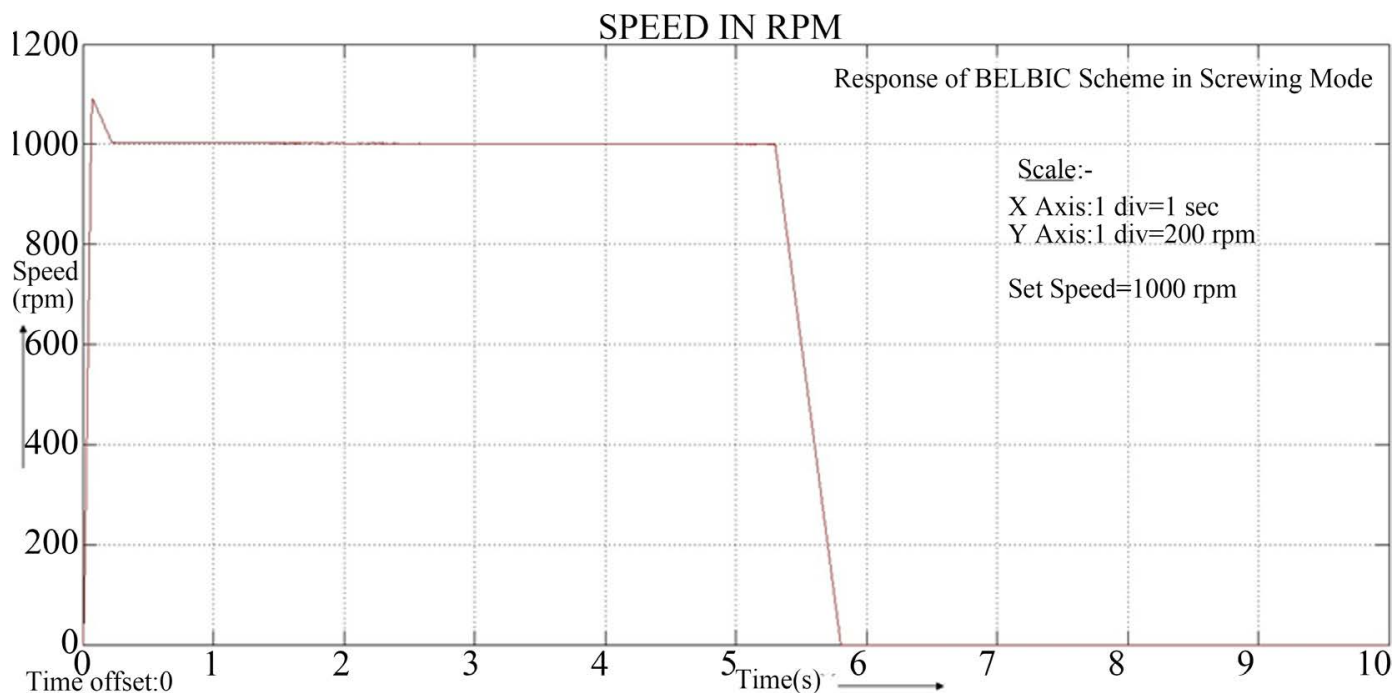

(b)

Figure 5. Simulation results. (a) Drilling mode; (b) Screwing mode.

\section{Performance Analysis}

In order to corroborate the simulation results a comparative analysis has been made between the simulated and experimental results. The values of peak overshoot, steady state error and the motor decelerating time have been tabulated and compared for various values of set speed.

Table 2 elucidates the performance characteristics of the chopper drive for various set speed values. From the simulated and experimental results the performance characteristic curves are plotted as shown in Figure 8. The peak overshoot and the steady state error values decreases with increase in set speed values. The peak overshoot and steady state error are very high at low set speed values. At higher set speeds, the proposed BELBIC controller provides superior performance by offering reduced peak overshoot and steady state error. These tabulated values substantiate that the proposed BELBIC controller scheme offers good steady state and transient state response. The Equation 6 which governs the motor dynamics corroborates the reduction of peak overshoot with respect to the set speed. The motor decelerating time is observed to be increasing for the rise in set speed values. Though the experimental and simulated values of peak overshoot and steady state values are in close agreement with each other, there is an appreciable amount of difference has been observed between simulated and experimental values as far as the deceleration time of the motor is concerned. This issue may be attributed to the 


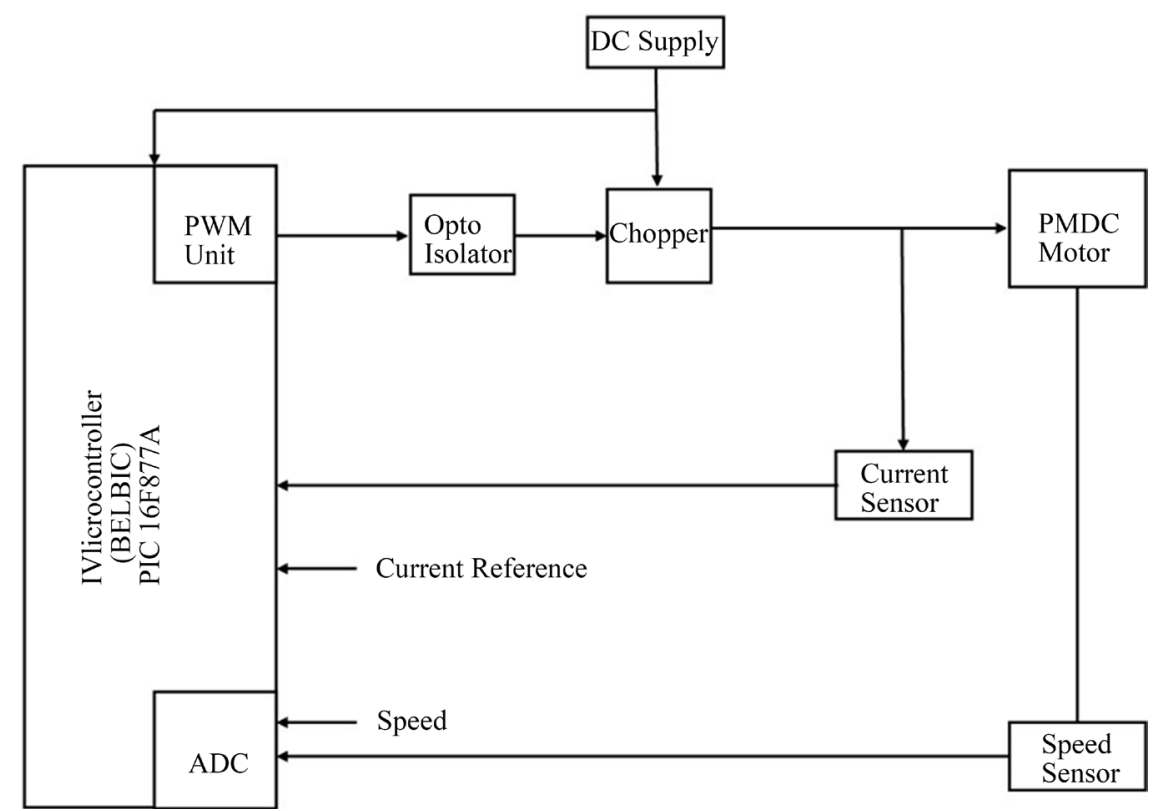

(a)

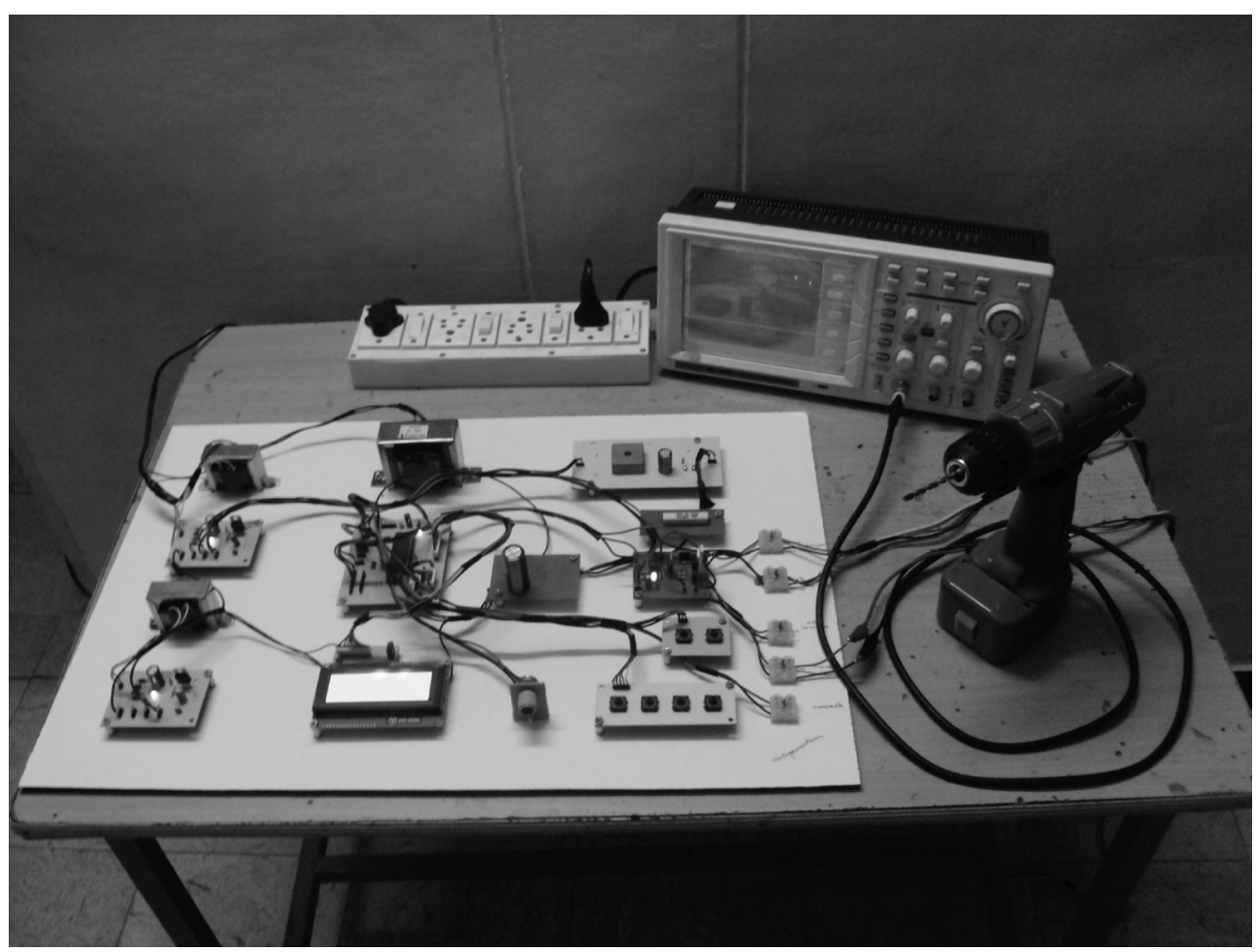

(b)

Figure 6. Experimental setup. (a) Block diagram; (b) Portrait of BELBIC hardware.

inherent problem associated with digital simulation of motor drives. It is known that any practical motor with appreciable moment of inertia takes longer deceleration time, which in turn depends on speed.

Table 3 compares and contrasts the performances of the conventional PI and the proposed BELBIC controller schemes. The corresponding analysis illustrated in Figure 9, depicts that the proposed BELBIC controller based chopper scheme has an edge over its conventional counterpart in terms of the steady state and transient state parameters. 


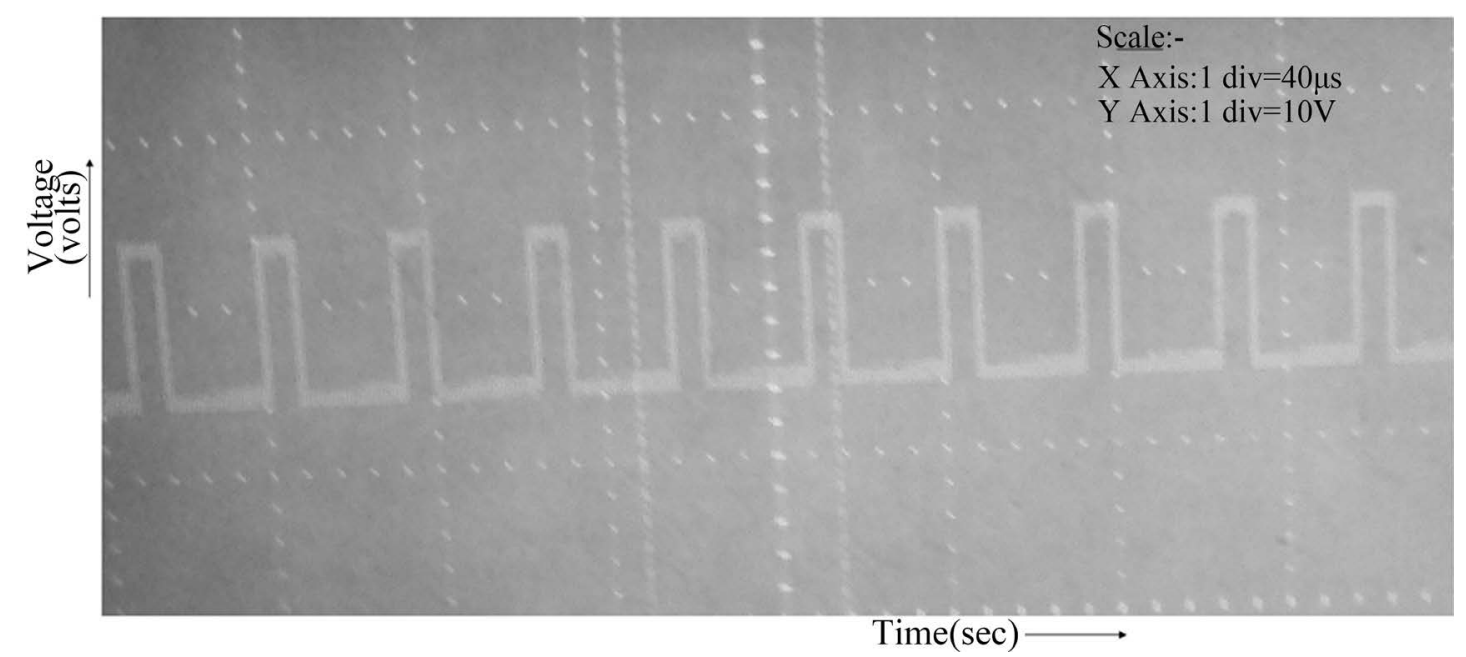

(a)

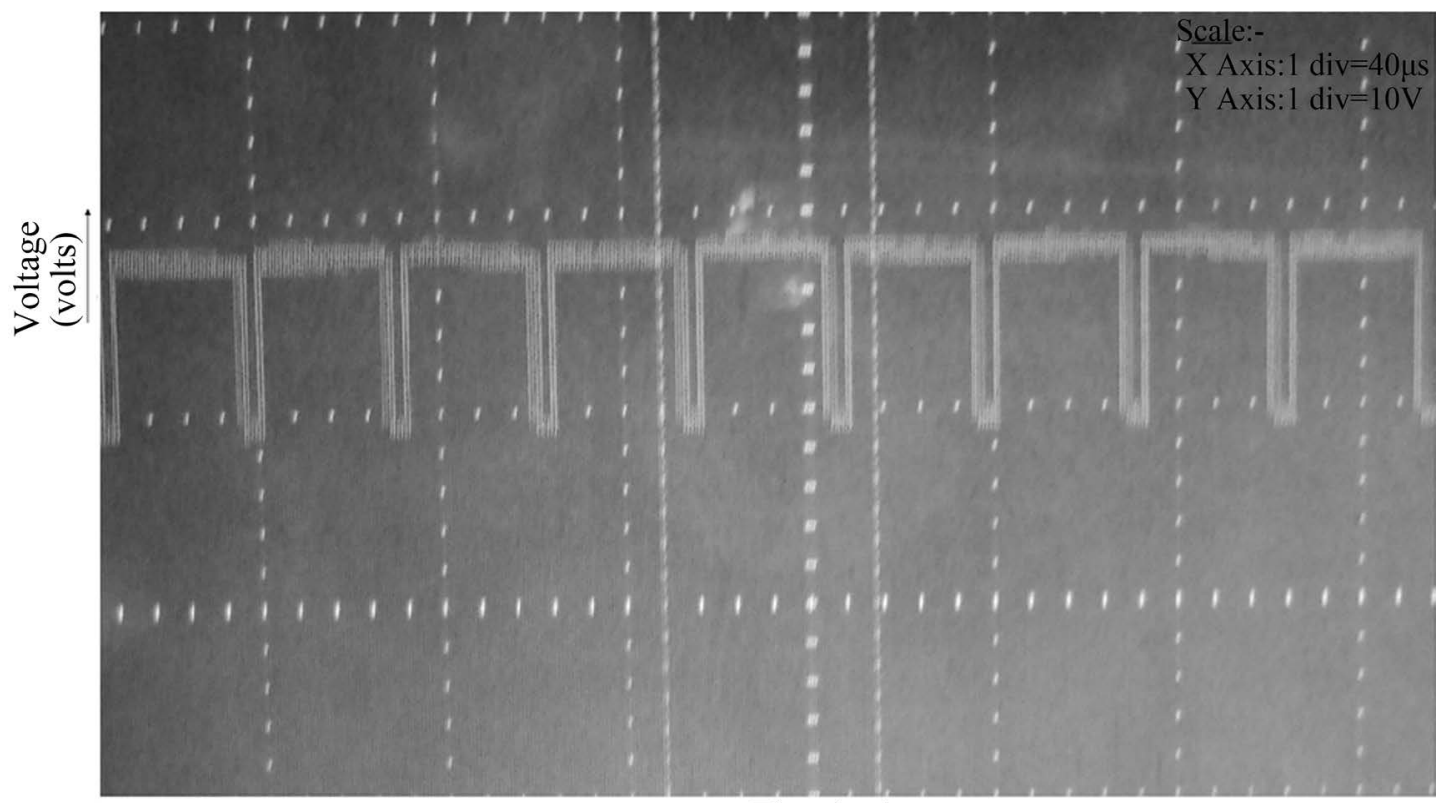

Time(sec)

(b)

Figure 7. Experimental results. (a) PWM signal for set speed = 900 rpm; (b) PWM signal for set speed $=1500$ rpm.

Table 2. Validation of experimental results of BELBIC drive.

\begin{tabular}{|c|c|c|c|c|c|c|}
\hline \multirow{2}{*}{$\begin{array}{c}\text { Set Speed } \\
\text { (RPM) }\end{array}$} & \multicolumn{2}{|c|}{ Peak Overshoot (\%) } & \multicolumn{2}{|c|}{ Steady State Error (\%) } & \multicolumn{2}{|c|}{ Motor Braking Time (s) } \\
\hline & Simulated & Measured & Simulated & Measured & Simulated & Measured \\
\hline 300 & 25 & 26 & 0.5 & 0.6 & 0.38 & 3.4 \\
\hline 600 & 13 & 13.8 & 0.4 & 0.52 & 0.42 & 4.9 \\
\hline 900 & 9.4 & 10.2 & 0.24 & 0.34 & 0.46 & 6.3 \\
\hline 1000 & 7.2 & 7.9 & 0.18 & 0.24 & 0.52 & 8.2 \\
\hline 1200 & 3.4 & 4.25 & 0.14 & 0.18 & 0.72 & 10.8 \\
\hline 1500 & 3 & 3.7 & 0.08 & 0.13 & 0.87 & 12.5 \\
\hline 2000 & 2 & 2.5 & 0.03 & 0.08 & 1.2 & 14.2 \\
\hline
\end{tabular}




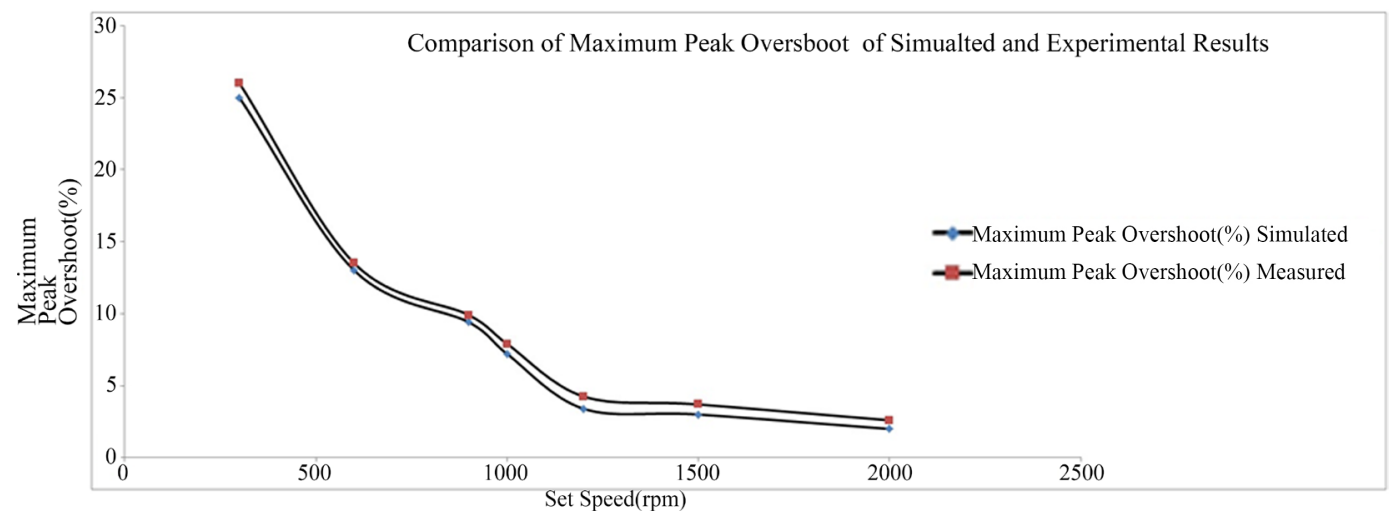

(a)

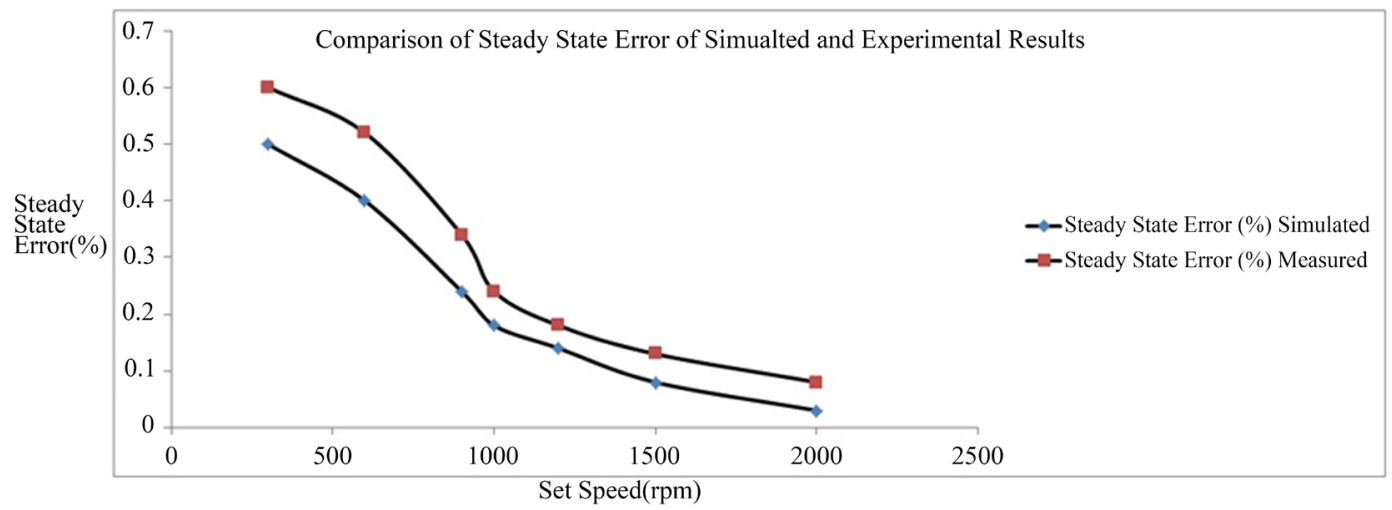

(b)

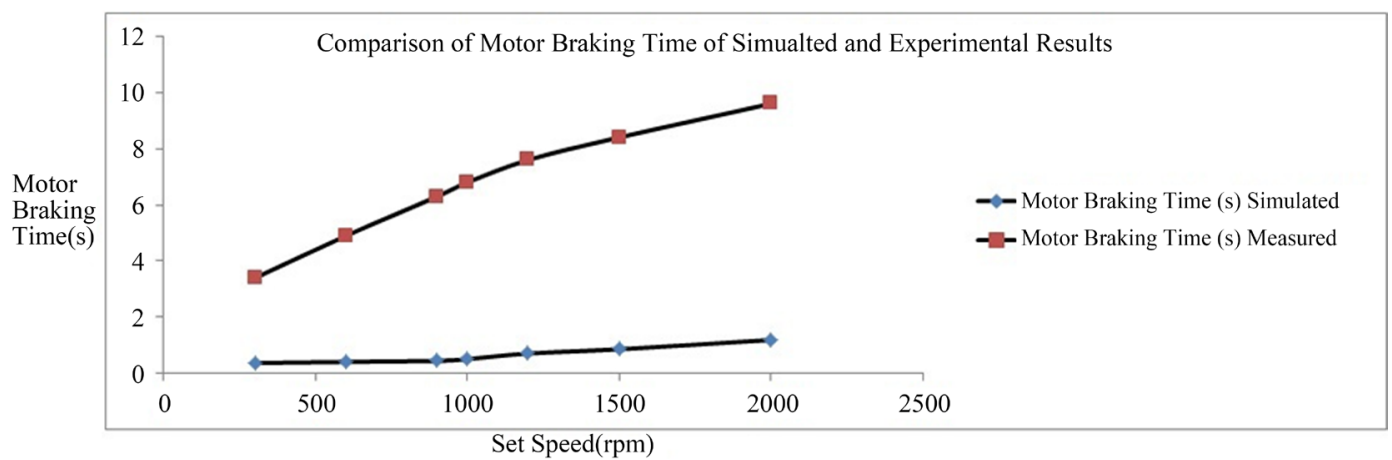

(c)

Figure 8. Comparative analysis of BEBIC simulated and experimental results. (a) Peak overshoot; (b) Steady state error; (c) Motor braking time.

Table 3. Comparative analysis of PI and BELBIC based drives.

\begin{tabular}{|c|c|c|c|c|c|c|}
\hline \multirow{2}{*}{ Set Speed (RPM) } & \multicolumn{2}{|c|}{ Peak Overshoot (\%) } & \multicolumn{2}{|c|}{ Steady State Error (\%) } & \multicolumn{2}{|c|}{ Motor Braking Time (s) } \\
\hline & PI & BELBIC & PI & BELBIC & PI & BELBIC \\
\hline 300 & 44 & 25 & 4.7 & 0.5 & 0.46 & 0.38 \\
\hline 600 & 25.7 & 13 & 2.5 & 0.4 & 0.55 & 0.42 \\
\hline 900 & 14.4 & 9.4 & 0.56 & 0.24 & 0.63 & 0.46 \\
\hline 1000 & 11.6 & 7.2 & 0.45 & 0.18 & 0.75 & 0.52 \\
\hline 1200 & 7.77 & 3.4 & 0.42 & 0.14 & 1.02 & 0.72 \\
\hline 1500 & 5.7 & 3 & 0.4 & 0.08 & 1.42 & 0.87 \\
\hline 2000 & 3.2 & 2 & 0.32 & 0.03 & 2.2 & 1.2 \\
\hline
\end{tabular}




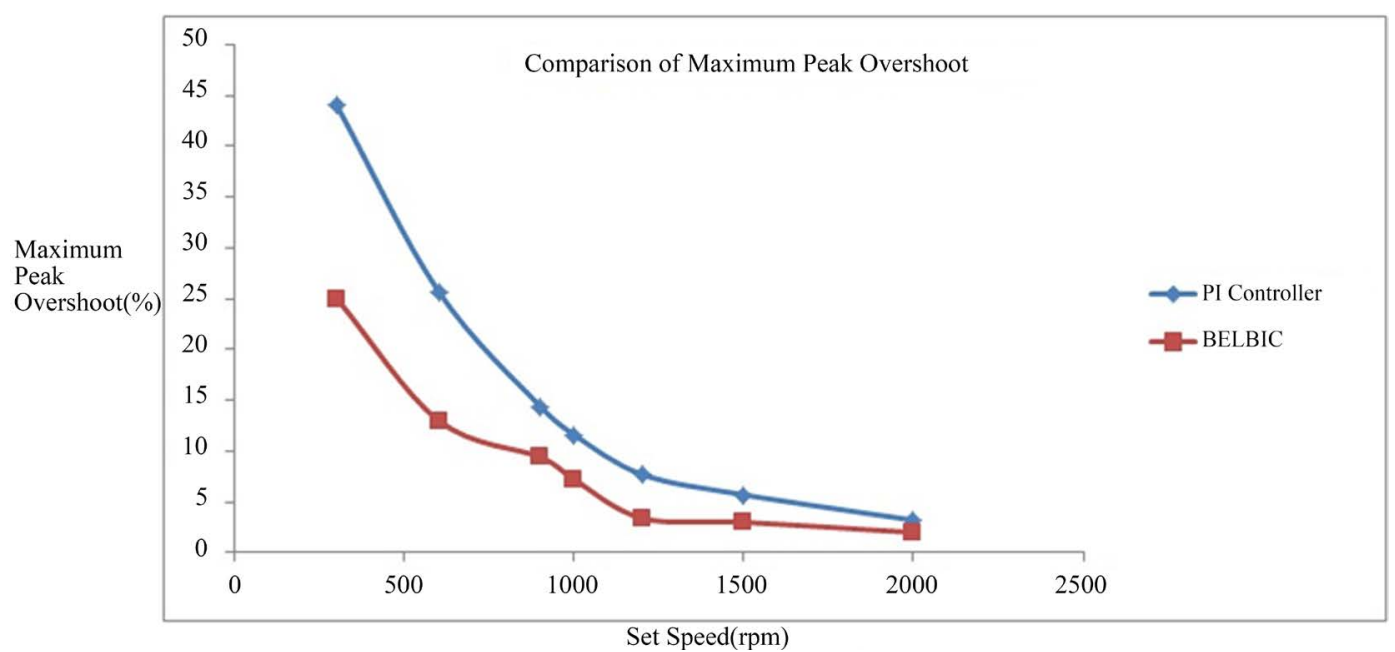

(a)

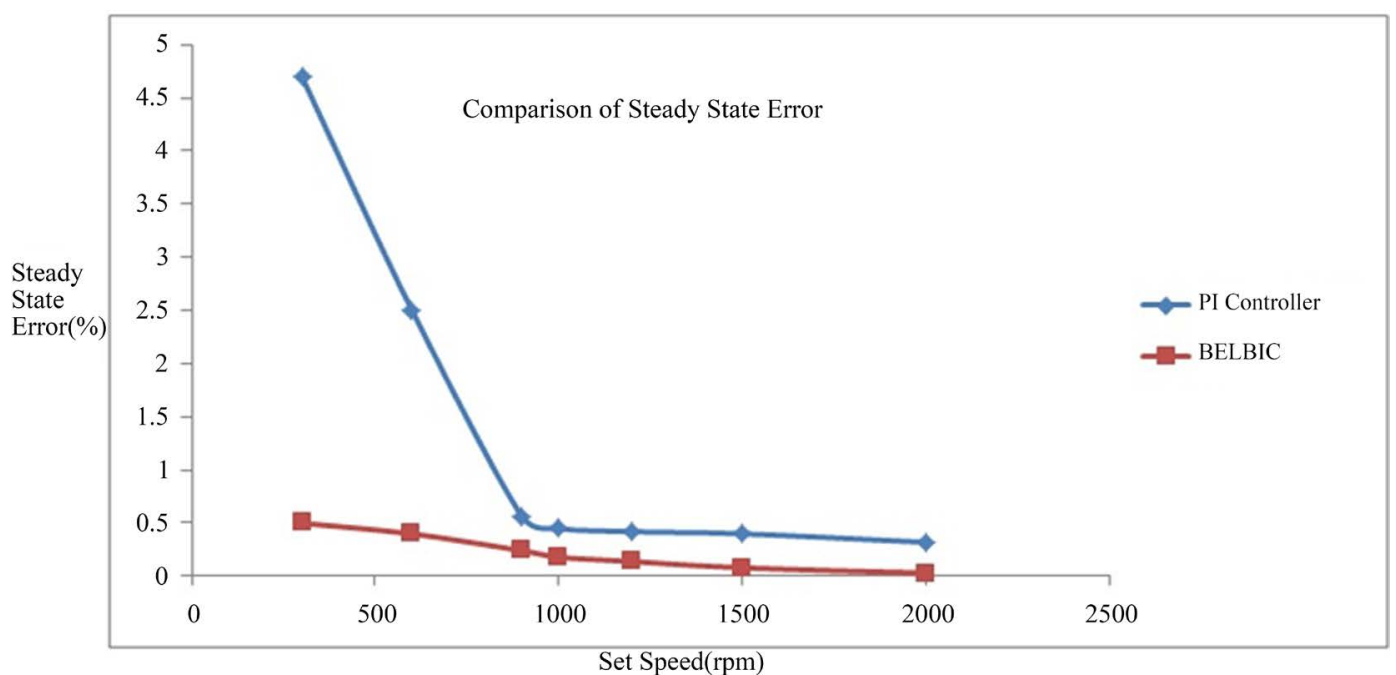

(b)

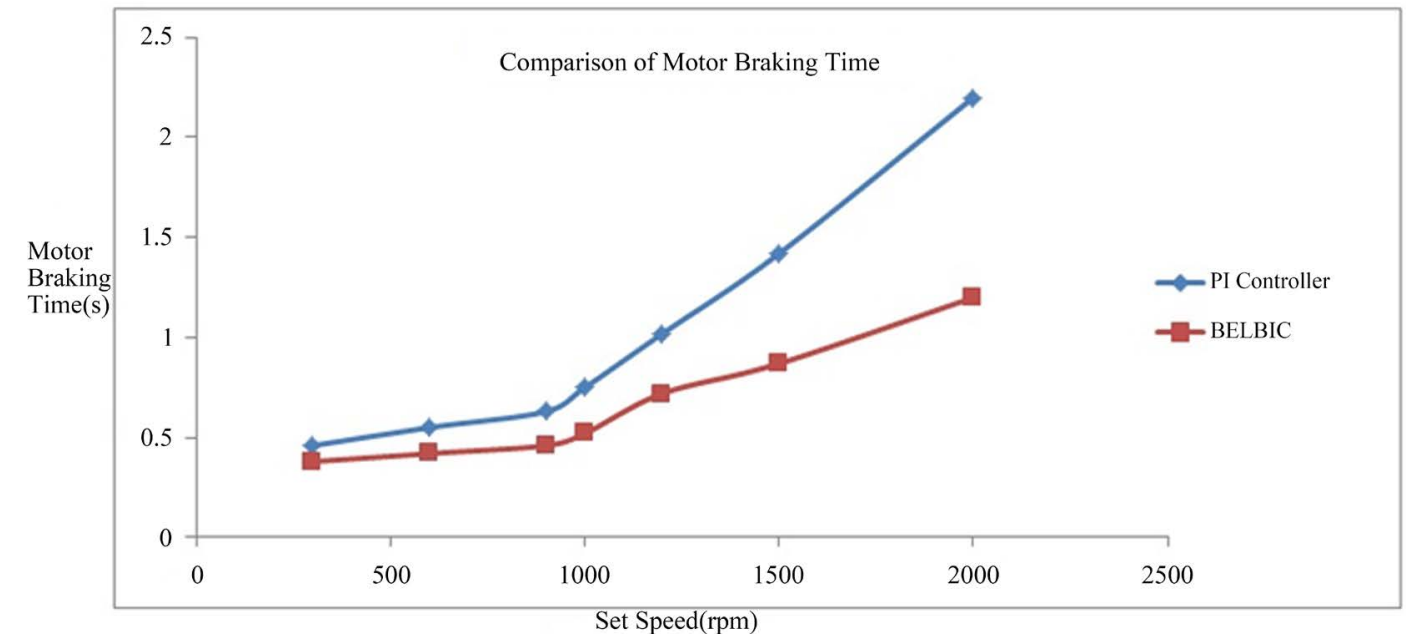

(c)

Figure 9. Comparative analysis of PI and BELBIC based drives. (a) Peak overshoot; (b) Steady state error; (c) Motor braking time. 


\section{Conclusion}

A BELBIC controller scheme based PMDC drive is proposed for orthopedic surgical simulators as it exhibits better transient and steady state performances when compared to traditional PI controller based systems. The proposed scheme has reduced peak overshoot, steady state error and decelerating time. As far as the chopper controlled PMDC motor drives used in orthopedic surgeries are concerned, the BELBIC scheme is more advantageous.

\section{References}

[1] Allotta, B., Belmonte, F., Dario, P. and Rinalidi, L. (1996) The Control of Penetration in a Mechatronic Drill for Orthopedic Surgery. Proceedings of Multi-Conference on Computational Engineering in Systems Applications-Robotics and Cybernetics, Lille, 222-227.

[2] Allotta, B., Giacalone, G. and Rinalidi, L. (1997) A Hand-Held Drilling Tool for Orthopedic Surgery. IEEE/ASME Transaction on Mechatronics, 2, 218-229. http://dx.doi.org/10.1109/3516.653046

[3] Baker, D., Brett, P.N., Griffiths, M.V. and Reyes, L. (1996) A Mechatronic Drilling for Ear Surgery: A Case Study of Some Design Characteristics. Mechatronics, 6, 461-477. http://dx.doi.org/10.1016/0957-4158(96)00006-2

[4] Baker, D., Brett, P.N., Griffiths, M.V. and Reyes, L. (1996) Surgical Requirements for the Stapedotomy Tool: Data and Safety Considerations. Proceedings of the 18th Annual International Conference of the IEEE Engineering in Medicine and Biology Society, Amsterdam, 31 October-3 November 1996, 214-215.

[5] Matthews, L.S. and Hirsch, C. (1972) Temperatures Measured in Human Cortical Bone When Drilling. Journal of Bone and Joint Surgery, 54, 297-308.

[6] Lavelle, C. and Wedgwood, D. (1980) Effect of Internal Irrigation on Frictional Heat Generated from Bone Drilling. Journal of Oral Surgery, 3, 499-503.

[7] Eriksson, A.R. and Albrektsson, T. (1984) Heat Caused by Drilling Cortical Bone. Temperature Measured in Vivo in Patients and Animals. Acta Orthopaedica Scandinavica, 55, 629-631. http://dx.doi.org/10.3109/17453678408992410

[8] Eriksson, R.A. and Albrektsson, T. (1984) The Effect of Heat on Bone Regeneration: An Experimental Study in the Rabbit Using the Bone Growth Chamber. Journal of Oral \& Maxillofacial Surgery, 42, 705-711. http://dx.doi.org/10.1016/0278-2391(84)90417-8

[9] Abouzgia, M.B. and Symington, J.M. (1996) Effect of Drill Speed on Bone Temperature. International Journal of Oral \& Maxillofacial Surgery, 25, 394-399. http://dx.doi.org/10.1016/S0901-5027(06)80040-8

[10] Natali, C., Ingle, P. and Dowell, J. (1996) Orthopedic Bone Drills-Can They Be Improved? Temperature Changes near the Drilling Face. Journal of Bone and Joint Surgery, 78-B, 357-362.

[11] Toews, A.R., Bailey, J.V., Townsend, H.G. and Barber, S.M. (1999) Effect of Feed Rate and Drill Speed on Temperatures in Equine Cortical Bone. American Journal of Veterinary Research, 60, 942-944.

[12] Bachus, K.N., Rondina, M.T. and Hutchinson, D.T. (2000) The Effects of Drilling Force on Cortical Temperatures and Their Duration: An in Vitro Study. Medical Engineering \& Physics, 22, 685-691. http://dx.doi.org/10.1016/S1350-4533(01)00016-9

[13] Bertollo, N. and Walsh, W.R. (2011) Drilling of Bone: Practicality, Limitations and Complications Associated with Surgical Drill-Bits. Biomechanics in Applications, 53-83.

[14] Hillery, M.T. and Shuaib, I. (1999) Temperature Effects in the Drilling of Human and Bovine Bone. Journal of Materials Processing Technology, Elseveir, 92-93, 302-308.

[15] Tsai, M.-D., Hsieh, M.-S. and Tsai, C.-H. (2007) Bone Drilling Haptic Interaction for Orthopedic Surgical Simulator. ELSEVIER —Computers in Biology and Medicine, 3, 1709-1718.

[16] Boiadjiev, T., Vitkov, V., Delchev, K., Zagurski, K., Chavdarov, I., Kastelov, R. and Boiadjiev, G. (2007) Robotized Module for Bone Drilling in Surgery: Experimental Setup and Results. Edition of Scientific Machine Union, 6, 7-12.

[17] Thomas, R., Bouazza-Marouf, K. and Taylor, G.J.S. (2008) Automated Surgical Screwdriver: Automated Screw Placement. Proceedings of the Institution of Mechanical Engineers, 222, 451-454. http://dx.doi.org/10.1243/09544119jeim375

[18] Murugananth, G. and Vijayan Dr., S. (2015) Development of Fuzzy Controlled Chopper Drive for Permanent Magnet DC Motor. Journal of Vibration and Control, 21, 555-562. http://dx.doi.org/10.1177/1077546313490184

[19] Murugananth, G., Vijayan, S. and Muthukrishnan, S. (2015) Experimental Validation of Fuzzy-Tuned AWPI Controller-Based Chpper Driven PMDC Motor. Journal of Testing and Evaluation, 43, 1383-1394.

http://dx.doi.org/10.1520/JTE20130284 
[20] Murugananth, G., Vijayan, S. and Muthukrishnan, S. (2013) Analysis of Various Anti-Windup Schemes Used to Control PMDC Motors Used in Orthopedic Surgical Simulators. Life Science Journal, 10, 226-230.

[21] Lucas, C., Shahmirzadi, D. and Sheikholeslami, N. (2004) Introducing BELBIC: Brain Emotional Learning Based Intelligent Controller. Intelligent Automation and Soft Computing, 10, 11-22. http://dx.doi.org/10.1080/10798587.2004.10642862

[22] Moren, J. (2002) Emotion and Learning: A Computational Model of the Amygdala. PhD Thesis, Lund University Cognitive Studies 93, Lund University, Lund.

[23] Jamali, M., Arami, R.A., Hosseini, B., Moshiri, B. and Lucas, C. (2008) Real Time Emotional Control for Anti-Swing and Positioning Control of SIMO Overhead Traveling Crane. International Journal of Innovative Computing, Information and Control, 4, 2333-2344.

[24] Jamali, M.R., Dehyadegari, M., Arami, A., Lucas, C. and Navabi, Z. (2010) Realtime Embedded Emotional Controller. Journal of Neural Computer and Applications, 19, 13-19. http://dx.doi.org/10.1007/s00521-008-0227-x

[25] Rahman, M., Milasi, A.R.M., Lucas, C., Arrabi, B.N. and Radwan, T.S. (2008) Implementation of Emotional Controller for Interior Permanent Magnet Synchronous Motor Drive. IEEE Transactions on Industrial Applications, 44, 1466-1476. http://dx.doi.org/10.1109/TIA.2008.2002206

[26] Jafari, E., Ali, M., Solaymani, S. and Shahgholian, G. (2013) Designing an Emotional Intelligent Controller for IPFC to Improve the Transient Stability Based on Energy Function. Journal of Electrical Engineering Technology, 8, 47884789. http://dx.doi.org/10.5370/JEET.2013.8.3.478

[27] Vijayakumar, T., Muthukrishnan, S. and Murugananth, G. (2016) Genetic Algorithm Based Speed Control of PMDC Motor Using Low Cost PIC 16F877A Microcontroller. Circuits and Systems, 7, 1334-1340. http://dx.doi.org/10.4236/cs.2016.78116

\section{Submit or recommend next manuscript to SCIRP and we will provide best service for you:}

Accepting pre-submission inquiries through Email, Facebook, LinkedIn, Twitter, etc.

A wide selection of journals (inclusive of 9 subjects, more than 200 journals)

Providing 24-hour high-quality service

User-friendly online submission system

Fair and swift peer-review system

Efficient typesetting and proofreading procedure

Display of the result of downloads and visits, as well as the number of cited articles

Maximum dissemination of your research work

Submit your manuscript at: http://papersubmission.scirp.org/ 